\title{
ИЗМЕНЕНИЕ СТРУКТУРНО-АГРЕГАТНОГО СОСТАВА СВЕТЛО-СЕРЫХ ЛЕСНЫХ ПОЧВ СЕВЕРНОГО ЗАУРАЛЬЯ В УСЛОВИЯХ ДЛИТЕЛЬНОЙ РАСПАШКИ
}

\author{
N.A. Gruzdeva, D.I. Eremin
}

\section{THE CHANGE OF STRUCTURAL AND AGGREGATE LIGHT-GRAY COMPOSITION OF FOREST SOILS OF THE NORTHERN TRANS-URALS UNDER LONG-TERM PLOWING CONDITIONS}

Груздева Н.A. - вед. агрохимик Государственной станции агрохимической службы «Тюменская», г. Тюмень.

E-mail: g.nessi@mail.ru

Еремин Д.И. - д-р биол. наук, проф. кафр. почвоведения и агрохимии Государственного аграрного университета Северного Зауралья, г. Тюмень. E-mail: soil-tyumen@yandex.ru

Структура является одним из главных агрофризических показателей почвы. От нее зависят водно-фризические и агрохимические свойства почвы, а также продуктивность пашни. Цель исследования - изучение влияния длительной распашки на структурное состояние светло-серых лесных почв. Структуру почвы определяли методом сухого просеивания через колонку сит; водопрочность агрегатов - путем рассева в воде. B статье представлены результаты исследования структурно-агрегатного состава пахотных $и$ светло-серых лесных почв (Luvic Retic Greyzemic Phaeozems (WRB)) Северного Зауралья. Исследования проводились в подтаежной зоне Тюменской области на стационаре станции химизации "Тюменская». Установлено, что светло-серые лесные почвы Северного Зауралья характеризуются отличным структурным состоянием гумусового слоя с хорошей водоустойчивостью почвенных агрегатов. Многолетняя распашка негативно отразилась на структурно-агрегатном составе изучаемых почв. Антропогенные изменения были отмечены вплоть до глубины 70 см. Пахотный слой характеризовался увеличением доли мелкозема (<0,25 мм) до 11-13\%, а при мокром просеивании - до 54-63 \%. Наиболее сильная диспергация была обнаружена у структурных отдельностей с размерами от 7
Gruzdeva N.A. - Leading Agrochemist, State Agrochemical Service Station "Tyumenskaya", Tyumen.

E-mail: g.nessi@mail.ru

Eremin D.I. - Dr. Biol. Sci., Prof., Chair of Soil Science and Agrochemistry, Northern Trans-Urals State Agrarian University, Tyumen.

E-mail: soil-tyumen@yandex.ru

до 3 мм. В подпахотных слоях отмечена тенденция формирования гльбистой структуры и повышения ее водоустойчивости. Средневзвешенный диаметр водоустойчивых почвенных агрегатов пахотного горизонта составляет 1,2-1,5 мм, что на 22-34 \% меньше значений целины. Полученные результаты исследования указывают на необходимость разработки системы земледелия для светло-серых лесных почв с учетом особенностей формирования их структурно-агрегатного состава, что позволит предотвратить проявление водной эрозии в виде запльвания или плоскостного смыва плодородного слоя на склоновых полях.

Ключевые слова: агрономически иенная структура, водоустойчивость, почвенный агрегат, антропогенное воздействие, ффизические свойства, пашня, подтайга, средневзвешенный диаметр.

The structure is one of the main agrophysical indicators of the soil. Water and physical and agrochemical properties of the soil, as well as the productivity of arable land depend on it. The aim of the research was to study the effect of prolonged plowing on structural state of light gray forest soils. The soil structure was determined by dry sieving through a column of sieves; water strength of aggregates - by sieving in water. The results of the 
research of structural and modular structure of arable and light gray forest soils (Luvic Retic Greyzemic Phaeozems (WRB) of the Northern Trans-Urals were presented in the study. The studies were carried out in taiga zone of Tyumen Region at the stationary chemicalization station "Tyumen". It was established that light gray forest soils of the Northern Trans-Urals were characterized by excellent structural condition of the humus layer with good water resistance of soil aggregates. Long-term plowing had a negative impact on structural and aggregate composition of studied soils. Anthropogenic changes were observed up to the depth of $70 \mathrm{~cm}$. Arable layer was characterized by an increase in the proportion of fine earth $(<0.25 \mathrm{~mm})$ to $11-13 \%$, and when wet sieving - to 54-63\%. The strongest dispersion was found in structural formations with sizes from 7 to $3 \mathrm{~mm}$. In sub-arable layers, the tendency of formation of a lumpy structure and increase of its water resistance was noted. The weighted average diameter of waterproof soil aggregates of arable horizon was 1.2$1.5 \mathrm{~mm}$, which was 22-34\% less than the values of virgin soil. The results received in the study indicate the need to develop the system of agriculture for light gray forest soils, taking into account the peculiarities of the formation of their structural and aggregate composition, which will prevent the manifestation of water erosion in the form of swimming or plane washout of fertile layer on slope fields.

Keywords: agronomically valuable structure, water resistance, soil aggregate, anthropogenic impact, physical properties, arable land, subtaiga, average diameter.

Введение. Серые лесные почвы занимают около 60 млн гектар, что составляет 3,5 \% территории Российской Федерации. Поскольку они располагаются преимущественно в зоне подтайги и северной части лесостепи, этот тип почв также активно используется в сельском хозяйстве наряду с черноземными. Особенно это касается Западной Сибири [1]. По данным кафедры почвоведения и агрохимии Государственного аграрного университета Северного Зауралья, тип серых лесных почв по площади занимает второе место, уступая подзолистым почвам. В целом их площадь составляет 6,3 \% территории юга Тюменской области. Серые лесные почвы обычно размещаются крупными массивами, гранича в подтаежной части с луговыми, а в лесостепной зоне - с черноземами. Этот тип почв обычно формируется на возвышенностях, тем самым привлекая сибирских аграриев распахивать прежде всего их, а не более богатые по гумусу и питательным веществам луговые почвы, расположенные в низинах.

На протяжении многих лет сельскохозяйственная наука изучала почвенные процессы в Сибири, создавала и испытывала новые сорта сельскохозяйственных культур, которые способны успешно произрастать в неблагоприятных почвенно-климатических условиях, и разрабатывала научно обоснованные системы удобрений и севооборотов, формируя единую школу сибирского земледелия [2-5]. Это привело к активному продвижению сельского хозяйства на север и восток нашей страны. Однако еще в прошлом столетии аграрии столкнулись с проблемой нехватки земельных ресурсов, поскольку основные площади черноземов были распаханы задолго до этого. В итоге распашке подверглись менее плодородные участки, занятые серыми лесными почвами.

Высокая антропогенная нагрузка, усиливающаяся ежегодно, привела к серьезному изменению естественного плодородия серых лесных почв, особенно наименее гумусированных ее подтипов - светло-серых и собственно серых лесных почв. В максимальной степени изменился количественный и качественный состав гумуса [6]. Это привело к изменению агрофизических свойств, главным из которых является структурно-агрегатный состав [7]. От структуры почвы зависят не только водно-фризические, но и ее химические свойства, а следовательно, продуктивность пашни [8]. Поэтому для успешного развития земледелия в Сибири необходимо детально изучить процесс изменения структурноагрегатного состава малогумусных почв в условиях многолетней распашки.

Цель исследований. Изучение влияния многолетней распашки на структурноагрегатный состав светло-серых лесных почв Северного Зауралья.

Задачи: фракционировать структурные агрегаты в сухом виде и в воде на отдельные фракции; рассчитать коэффициенты структурности и водопрочности для различных слоев светло- 
серой лесной почвы; выделить наименее устойчивые фракции почвы и провести сравнительный анализ значений целинного и пахотного участков.

Объекты и методы. Серые лесные почвы Luvic Retic Greyzemic Phaeozems (WRB) занимают повышенные элементы рельефра, которые хорошо обеспечены поверхностным стоком и имеют глубокий уровень залегания грунтовых вод. Они формируются под мелколиственными березовыми и осиновыми лесами при одновременном действии двух современных процессов почвообразования - гумусово-аккумулятивного и оподзоливания. Многолетние исследования динамики плодородия пахотных серых лесных почвы Зауралья охватили все их подтипы. Стационарный участок был заложен в 1994 г. агрохимической станцией «Тюменская». Стационар 28 расположен в 3 км от д. Усалка Ярковского р-на, в подтаежной зоне (57018'24" с.ш.; 66056'25" в.Д.). Почва светло-серая лесная, среднесуглинистая на лессовидном суглинке.

Для изучения структурно-агрегатного состава светло-серых лесных почв использовали целинный участок, находящийся на расстоянии 200 м от стационара. Формула строения почвенного профиля изучаемой светло-серой лесной почвы выглядит следующим образом:

Целинная: $\mathrm{A0}$ (1 cм) $-\mathrm{A} 1(11 \mathrm{~cm})-\mathrm{A} 1 \mathrm{~A} 2$ $(10 \mathrm{~cm})-\mathrm{B} 1(32 \mathrm{~cm})-\mathrm{B} 2(50 \mathrm{~cm})-\mathrm{BC}(60 \mathrm{~cm})-\mathrm{C}$.

Пахотная: $\mathrm{A}_{\text {пах. }}(20 \mathrm{~cm})-\mathrm{B} 1(30 \mathrm{~cm})-\mathrm{B} 2$ (55 см) BC (60 см) - C.

За период с 1994 по 2016 г. на стационаре было внесено 230 т/га органических удобрений в виде торфонавозного компоста, который состоял из низинного торфа и навоза КРС в соотношении 1:3. Было запахано 28 т пожнивнокорневых остатков преимущественно зерновых культур. С минеральными удобрениями в почву поступило 361 кг азота; 140 кг фосффора и 140 кг калия.

На целинных светло-серых лесных почвах подтаежной зоны произрастают березовоосиновые леса с хорошо развитым травянистым покровом, где доминируют следующие растения: мятлик луговой (Poa pretensis L.); костер безостый (Bromus inermis L.); полевица обыкновенная (Aqrostis vulgaris L.); тимофреевка луговая (Phleum pratense L.); лабазник вязолистный (Filipendula ulmaria L.); вейник наземный
(Calamagrostis epigejos L. Roth.); чина луговая (Lathyrus pratensis L.); клевер луговой (Trifolium pratense L.); мышиный горошек (Vicia cracca L.); тысячелистник обыкновенный (Achillea millefolium L.); девясил высокий (Inula helenium L.); герань лесная (Geranium sylvaticum L.); земляника (Fragaria vesca L.).

Почвенные образцы отбирались после уборки сельскохозяйственных культур, непосредственно перед вспашкой. На целинном участке отбор образцов проводили в тот же день, что и на поле. Пробы отбирали послойно с интервалом 10 см на глубину до 70 см в 6-кратной повторности. Определение структурно-агрегатного состава проводили в лаборатории кафедры почвоведения и агрохимии ГАУ Северного Зауралья.

Структуру почвы определяли методом сухого просеивания через колонку сит с разным диаметром отверстий. После получения данных рассчитывали коэфффициент структурности по формуле

$$
K_{c m p}=\frac{\sum(10-0,25 M M)}{\sum(>10 M \mathcal{M}+<0,25 M M)} .
$$

Агрегатный состав изучали путем мокрого просеивания в приборе Бакшеева с последующим пересчетом суммы агрегатов с размерами более 0,25 мм.

Средневзвешенный диаметр (СВД) агрегатов (для сухого и мокрого просеивания) необходим для анализа структурного состояния (чем выше значение, тем крупнее агрегаты, значения менее 1 мм указывают на распыленность почвы). СВД (мм) рассчитывали по формуле

$$
\text { СВД }=\frac{d_{1} \cdot p_{1}+d_{2} \cdot p_{2}+\ldots+d_{n} \cdot p_{n}}{100},
$$

где $d_{1}, d_{2}, d_{n}-$ средний диаметр фрракций, мм; $p_{1} p_{2} p_{n}$ - содержание данной фрракции, \%.

Статистическая обработка проводилась по Доспехову.

Результаты исследований и их обсуждение. Ситовой рассев показал, что целинная светло-серая лесная почва обладает достаточно хорошим структурным составом для малогумусных почв. На долю глыбистых агрегатов 
(>10 мм) в слое 0-30 см приходилось 18,227,0 \% (табл. 1). С глубиной содержание крупных структурных агрегатов увеличивалось, что характерно для иллювиального горизонта.

Содержание распыленных частиц (<0,25 мм) варьировало по почвенному профилю в пределах от 3,8 до 10,1 \%, что отличает исследуемые почвы Тюменской области от других регионов Западной Сибири [8]. Причиной этого являются особенности гранулометрического состава, выражаемые в повышенном содержании фракций средней и мелкой пыли, способной при высушивании цементироваться в агрегаты [9].

На долю агрономически ценных фрракций (АЦФ) в гумусовом слое приходится 70-72 \%, что соответствует отличному структурному состоянию. Это также подтверждает и коэфффициент структурности, который составляет 2,42,6 ед. (табл. 3). С глубины 30 см данный показатель уменьшается, достигая минимума 2,6 ед. в слое 70-80 см. Причиной этого является формирование глыбистых агрегатов и аккумуляция илистых частиц в процессе иллювиирования [10].

Наиболее важными фракциями в почве принято считать структурные отдельности с размерами 5-3 и 3-2 мм. При высоком их содержании в почве складываются оптимальные условия для развития корневой системы растений и активной деятельности микрофрлоры. В анализируемых светло-серых лесных почвах содержание этих фракций в сумме не превышает $20 \%$.

Средневзвешенный диаметр почвенных агрегатов гумусового слоя составляет 3,7-4,6 мм; глубже - 4,9-6,1 мм. Данный фракт обуславливает хорошую аэрацию светло-серых лесных почв до глубины 70-80 см, но только в сухом состоянии, что в условиях Западной Сибири бывает кратковременным.

Таблица 1

Структурный состав светло-серой лесной почвы (сухое просеивание)

\begin{tabular}{|c|c|c|c|c|c|c|c|c|c|c|c|}
\hline \multirow{2}{*}{ Слой, см } & \multicolumn{10}{|c|}{ Фракция, мм } \\
\cline { 2 - 12 } & $>10$ & $10-7$ & $7-5$ & $5-3$ & $3-2$ & $2-1$ & $1,0-0,5$ & $0,5-0,25$ & $<0,25$ & АЦФ \\
\hline \multicolumn{10}{|c|}{ Лес } \\
\hline $0-10$ & 25,4 & 13,2 & 8,6 & 10,2 & 7,7 & 10,5 & 12,2 & 8,4 & 3,8 & 70,8 \\
\hline $10-20$ & 18,2 & 10,4 & 7,8 & 10,5 & 7,4 & 14,2 & 17,9 & 3,7 & 9,9 & 71,9 \\
\hline $20-30$ & 27,0 & 9,6 & 5,6 & 14,8 & 5,2 & 8,6 & 8,6 & 9,6 & 11 & 62,0 \\
\hline $30-40$ & 29,6 & 11,8 & 9,0 & 9,5 & 9,8 & 5,3 & 10,7 & 4,2 & 10,1 & 60,3 \\
\hline $40-50$ & 40,2 & 12,3 & 12,3 & 6,4 & 6,5 & 3,4 & 10,3 & 3,3 & 5,3 & 54,5 \\
\hline $50-60$ & 40,4 & 14,4 & 10,4 & 12,7 & 4,0 & 4,7 & 5,6 & 1,7 & 6,1 & 53,5 \\
\hline $60-70$ & 40,6 & 10,6 & 7,2 & 10,3 & 4,3 & 5,3 & 7,1 & 4,8 & 9,8 & 49,6 \\
\hline \multicolumn{10}{|c|}{ Пашня } \\
\hline $0-10$ & 18,6 & 10,5 & 6,2 & 4,5 & 8,1 & 12 & 16,8 & 10,1 & 13,2 & 68,2 \\
\hline $10-20$ & 16,3 & 9,0 & 5,4 & 5,2 & 8,0 & 15,7 & 21,4 & 8,0 & 11,0 & 72,7 \\
\hline $20-30$ & 27,5 & 7,3 & 3,6 & 8,9 & 6,3 & 11,6 & 9,5 & 12,6 & 12,7 & 59,8 \\
\hline $30-40$ & 35,3 & 14,5 & 3,2 & 8,6 & 12,2 & 6,4 & 11,7 & 4,5 & 3,6 & 61,1 \\
\hline $40-50$ & 38,7 & 14,0 & 6,4 & 8,5 & 8,4 & 4,1 & 11,6 & 5,8 & 2,5 & 58,8 \\
\hline $50-60$ & 40,2 & 13,6 & 9,1 & 10,2 & 4,7 & 3,5 & 6,4 & 7,6 & 4,7 & 55,1 \\
\hline $60-70$ & 45,4 & 11,4 & 8,4 & 10,8 & 3,0 & 3,8 & 8,6 & 6,3 & 2,3 & 52,3 \\
\hline
\end{tabular}

Ежегодные механические обработки, перевороты пласта и дефицит растительных остатков привели к изменению структурного состояния светло-серой лесной почвы. Максимальные изменения произошли в слое 0-40 см, причем необходимо отметить дифференциацию этого слоя по содержанию глыбистых агрегатов и мелкозема $(<0,25$ мм). Пахотный слой, который ссормировали толщиной $20 \mathrm{~cm}$, состоял из 1618,6 \% глыбистых агрегатов и 11-13,2 \% пылеватой фракции. Очевиден фракт антропогенного распыления почвы, поскольку на целине содер- 
жание агрегатов размером менее 0,25 мм было существенно ниже. Это обусловлено двумя причинами: ухудшением гумусового состояния и усилением процесса миграции физической глины вниз по почвенному профилю. С 40 см отмечаются серьезное повышение глыбистости и уменьшение содержания агрегатов с размерами менее 0,25 мм. Это объясняется активным цементированием агрегатов и формированием плужной подошвы. В условиях Северного Зауралья это может привести к нарушению водопроницаемости почвы $и$ eе переувлажнению [11].

Максимальной диспергации подвергалась часть агрономически ценной фракции с размерами от 3 до 10 мм, содержание которых было достоверно ниже, чем на целинном участке. Количество агрегатов с размерами 2,0-0,25 мм, напротив, возросло, что указывает на определенную устойчивость светло-серой лесной почвы к антропогенному действию. Однако эта устойчивость существенно ниже в сравнении с высокогумусными почвами, поэтому при сохранении высокой антропогенной нагрузки произойдет ухудшение структурного состояния светло-серых лесных почв быстрее, чем черноземов Зауралья [12, 13].

Расчет коэффициента структурности и средневзвешенного диаметра (СВД) агрегатов также указывает на антропогенные изменения. При сравнении с целиной коэффрициент структурности и СВД уменьшились в меньшей степени, поскольку крупные агрегаты рассыпались на мелкие структурные отдельности, которые, в свою очередь, компенсировали их содержание.

Мокрое просеивание показывает качественную характеристику структурно-агрегатного состава почв. Вода оказывает жесткое воздействие на почвенные агрегаты, заставляя их в большей степени распадаться. Поэтому часто этот показатель называют водоустойчивостью агрегатов. В природе способность почвенных агрегатов размокать очень важна, поскольку от нее зависит поровая характеристика и водопроницаемость почвенного профиля [11].

Наши исследования показали, что содержание пылеватых агрегатов (<0,25 мм) в целинной светло-серой лесной почве значительно выше, чем при сухом просеивании. По всей глубине (до 70 см) на его долю приходилось 45,9-53,0 \%, что соответствовало хорошей водоустойчивости (табл. 2). Наиболее водопрочными были агрегаты размером более 3 мм - их содержание существенно не отличалось от результатов сухого просеивания. Однако фракции 3,0-0,25 мм подверглись максимальной диспергации, что и обусловило высокое содержание частиц размером менее 0,25 мм при мокром просеивании. Полученные результаты указывают на то, что структурные агрегаты с размером менее 3 мм являются несформировавшимися и особенно уязвимыми при каком-либо воздействии.

Средневзвешенный диаметр водоустойчивых агрегатов целинной светло-серой лесной почвы составил 1,8-1,9 мм для слоя 0-20 см. С глубиной отмечается уменьшение диаметра структурных отдельностей до 0,8-1,0 мм. В условиях Западной Сибири это может оказать негативное влияние на водопроницаемость светло-серых лесных почв и возникновение анаэробных процессов на глубине более $40 \mathrm{~cm}$.

Длительная распашка привела к снижению водопрочности агрегатов пахотной светло-серой лесной почвы. Содержание мелкозема возросло до 50,9-63,2 \% в слое 0-40 см, что соответствовало удовлетворительной водоустойчивости. Глубже 40 см содержание мелкозема уменьшилось, что указывает на определенный процесс цементации в более крупные агрегаты. На наш взгляд, это обусловлено проникновением илистых частиц из вышележащих слоев и участием их в процессе формирования макроагрегатов.

Средневзвешенный диаметр водоустойчивых агрегатов пахотного слоя (0-20 см) составил 1,2-1,5 мм, что на 22-34 \% меньше относительно целины. Нами была выявлена тенденция распыления почвенных агрегатов при многолетней распашке светло-серых лесных почв. На склоновых полях подтаежной зоны уменьшение размеров структурных отдельностей может привести к появлению водной эрозии и смыву плодородного слоя со всеми элементами минерального питания [14]. Этому будет также способствовать снижение водоустойчивости почвенных агрегатов. 
Агрегатный состав светло-серой лесной почвы (мокрое просеивание)

\begin{tabular}{|c|c|c|c|c|c|c|c|}
\hline \multirow{2}{*}{ Слой, см } & \multicolumn{7}{c|}{ Фракция, мм } \\
\cline { 2 - 8 } & $>7$ & $7-5$ & $5-3$ & $3-1$ & $1-0,5$ & $0,5-0,25$ & $<0,25$ \\
\hline \multicolumn{7}{|c|}{ Лес } \\
\hline $0-10$ & 10,2 & 12,0 & 5,3 & 11,6 & 5,5 & 3,2 & 52,2 \\
\hline $10-20$ & 14,0 & 7,8 & 9,7 & 8,6 & 8,3 & 5,7 & 45,9 \\
\hline $20-30$ & 8,2 & 6,4 & 5,8 & 14,2 & 9,8 & 5,6 & 50,0 \\
\hline $30-40$ & 6,3 & 5,7 & 6,2 & 12,7 & 11,1 & 8,8 & 49,2 \\
\hline $40-50$ & 4,1 & 8,4 & 9,0 & 12,1 & 14,5 & 9,0 & 42,9 \\
\hline $50-60$ & 3,6 & 4,2 & 9,2 & 7,5 & 17,1 & 9,5 & 48,9 \\
\hline $60-70$ & 2,6 & 2,6 & 5,2 & 7,2 & 18,7 & 10,7 & 53,0 \\
\hline \multicolumn{7}{|c|}{ Пашня } \\
\hline $0-10$ & 6,8 & 5,7 & 3,9 & 7,7 & 6,8 & 5,9 & 63,2 \\
\hline $10-20$ & 12,3 & 3,6 & 6,2 & 7,2 & 9,2 & 6,6 & 54,9 \\
\hline $20-30$ & 6,2 & 5,7 & 4,0 & 10,3 & 12,6 & 6,8 & 54,4 \\
\hline $30-40$ & 7,7 & 4,2 & 6,5 & 10,5 & 10,8 & 9,4 & 50,9 \\
\hline $40-50$ & 5,3 & 8,9 & 7,3 & 13,7 & 16,4 & 9,3 & 39,1 \\
\hline $50-60$ & 4,6 & 5,8 & 10,3 & 8,6 & 17,6 & 8,2 & 44,9 \\
\hline $60-70$ & 3,3 & 3,6 & 6,9 & 8,9 & 17,0 & 10,5 & 49,8 \\
\hline
\end{tabular}

В подпахотном слое (20-30 см) также произошло разрушение агрономически ценной фракции. Изменение по отношению к целине составляет $17 \%$, однако снижение водопрочности агрегатов несколько меньше относительно пахотного слоя. Ухудшение водопрочности обусловлено использованием периодической глу- бокой вспашки, которую хозяйство могло проводить в отдельные годы на фоне дефицита растительных остатков в этом слое из-за формирования поверхностной корневой системы зерновыми культурами. К сожалению, установить точную причину ухудшения водопрочности агрегатов не представляется возможным.

Таблица 3

\section{Расчетные показатели структурно-агрегатного состояния светло-серых лесных почв}

\begin{tabular}{|c|c|c|c|c|c|c|c|c|}
\hline \multirow{3}{*}{$\begin{array}{c}\text { Слой, } \\
\text { см }\end{array}$} & \multicolumn{4}{|c|}{ Сухое просеивание } & \multicolumn{4}{|c|}{ Мокрое просеивание } \\
\hline & \multicolumn{2}{|c|}{ Лес (целина) } & \multicolumn{2}{|c|}{ Пашня } & \multicolumn{2}{|c|}{ Лес (целина) } & \multicolumn{2}{|c|}{ Пашня } \\
\hline & $K_{\text {стр. }}$ & СВД, мм & $\mathrm{K}_{\text {стр. }}$ & СВД, мм & $\begin{array}{c}\text { Водо- } \\
\text { проч- } \\
\text { ность, \% }\end{array}$ & СВД, мм & $\begin{array}{c}\text { Водо- } \\
\text { проч- } \\
\text { ность, \% }\end{array}$ & СВД, мм \\
\hline $0-10$ & 2,4 & 4,6 & 2,1 & 3,5 & 48 & 1,8 & 36,8 & 1,2 \\
\hline 10-20 & 2,6 & 3,7 & 2,7 & 3,2 & 54 & 1,9 & 45,1 & 1,5 \\
\hline $20-30$ & 1,6 & 4,4 & 1,5 & 4,1 & 50 & 1,4 & 45,6 & 1,2 \\
\hline $30-40$ & 1,5 & 4,9 & 1,6 & 5,3 & 51 & 1,2 & 49,1 & 1,3 \\
\hline $40-50$ & 1,2 & 5,9 & 1,4 & 5,7 & 57 & 1,3 & 60,9 & 1,4 \\
\hline $50-60$ & 1,2 & 6,1 & 1,2 & 5,9 & 51 & 1,0 & 55,1 & 1,2 \\
\hline $60-70$ & 1,0 & 5,7 & 1,1 & 6,2 & 47 & 0,8 & 50,2 & 0,9 \\
\hline
\end{tabular}

Примечание. Кстр - коэффрициент структурности; СВД - средневзешенный диаметр агрегатов. 
Начиная с глубины 40 см нами было отмечено формирование более крупных водоустойчивых почвенных агрегатов по сравнению с целинным участком. Их средневзвешенный диаметр составил 0,9-1,4 мм, что на 6-19\% выше значений целины. Причиной укрупнения структурных отдельностей является аккумуляция илистых частиц из пахотного слоя, которые участвуют в структурообразовании.

\section{Выводы}

1. Светло-серые лесные почвы Северного Зауралья характеризуются отличным структурным состоянием гумусового слоя, где содержание агрономически ценных агрегатов (100,25 мм) достигает 70-72 \%, а коэффрициент структурности составляет 2,4-2,6 ед. Водопрочность агрегатов варьирует от 48 до $54 \%$. В более глубоких слоях пахотной светло-серой лесной почвы коэфффициент структурности уменьшается за счет формирования водопрочной глыбистой структуры. Средневзвешенный диаметр агрегатов уменьшается до 0,8-1,4 мм. Это свидетельствует о естественной склонности к распылению.

2. Многолетняя распашка светло-серых лесных почв привела к ухудшению структурноагрегатного состава до глубины 70 см. На долю мелкозема (<0,25 мм) при сухом просеивании приходится 11-13\%, а при мокром рассеве 54-63 \%, что значительно выше показателей целинного участка.

3. Почвенный профиль пахотных светлосерых лесных почв четко диффреренцирован по структурно-агрегатному составу. В пахотном слое коэфффициент структурности составляет 2,1-2,7 ед. Водопрочность почвенных агрегатов варьирует в пределах от 37 до $45 \%$, что соответствует хорошей водоустойчивости.

4. Установлена тенденция распыления пахотного слоя светло-серых лесных почв под действием механических обработок. Средневзвешенный диаметр водоустойчивых агрегатов составляет 1,2-1,5 мм, что на 22-34 \% меньше размера структурных отдельностей целинного участка. При интенсивном использовании светло-серых лесных почв без учета их особенностей возможно проявление водной эрозии в виде заплывания или смыва плодородного слоя.

\section{Литература}

1. Ренев Е.П., Еремин Д.И., Еремина Д.В. Оценка основных показателей плодородия почв, наиболее пригодных для расширения пахотных угодий в Тюменской области //Достижение науки и техники АПК. - 2017. T. 31. - № 4. - C. 27-31.

2. Фисунов Н.В., Федоткин В.А., Иваненко А.С. Эффрективность возделывания яровой и озимой пшеницы в Тюменской области // Агропродовольственная политика России. 2015. - № 10 (46). - С. 38-41.

3. Еремин Д.И. Продуктивность зернового с занятым паром севооборота в условиях Северного Зауралья: автореф. дис. ... канд. с.-Х. наук. - Тюмень, 2002. - 18 с.

4. Абрамов Н.В., Шерстобитов С.В. Диффреренцированное внесение удобрений с использованием спутниковой навигации // Агрохимия. - 2018. - № 9. - С. 40-49. DOI: 10.1134/S000218811809003X.

5. Любимова А.В., Еремин Д.И. Изучение генетического разнообразия сортов овса сибирской селекции по авенин-кодирующим локусам // Агропродовольственная политика России. - 2017. - № 9 (69). - С. 70-74.

6. Еремин Д.И., Груздева Н.А., Еремина Д.В. Изменение гумусового состояния серых лесных почв Восточной окраины Зауральского Плато под действием длительной распашки // Почвоведение. - 2018. - № 7. - С. 826-835. DOI: $10.1134 / \mathrm{S} 0032180 \times 18070110$.

7. Кураченко Н.Л. Морфология структурной организации черноземов и серых лесных почв Красноярской лесостепи // Вестник КрасГАУ. - 2009. - № 2. - С. 28-33.

8. Кураченко Н.Л., Хижняк С.В. Пространственное варьирование структурно-агрегатного состава черноземов и серых лесных почв Красноярской лесостепи в предельно однородных условиях почвообразования // Вестник Алтайского ГАУ. - 2010. № 1 (63). - С. 35-40.

9. Еремин Д.И., Груздева Н.А. Влияние антропогенного фактора на микроагрегатный состав серых лесных почв // Сибирский вестник сельскохозяйственной науки. - 2018. T. 48. - № 1. - C. 28-37. DOI: 10.26898/03708799-2018-1-4. 
10. Еремин Д.И., Груздева Н.А. Гранулометрия пахотных серых лесных почв Северного Зауралья // Известия Оренбургского ГАУ. 2018. - № 1 (69). - C. 18-22.

11. Eremin D.I., Eremina D.V. (2017). Influence of transport infrastructure on water permeability of soil of Western Siberia. IOP Conference Series: Earth and Environmental Science 90. DOI: org/10.1088/1755-1315/90/1/012111.

12. Рзаева В.В. Качество основной обработки почвы в северной лесостепи Тюменской области // Вестник КрасГАУ. - 2017. - № 12 (135). - C. 29-33.

13. Груздева Н.А., Котченко С.Г., Еремин Д.И. Динамика содержания и запасов гумуса в агросерых лесных почвах Северного Зауралья // Плодородие. - 2017. - № 3 (96). C. 16-19.

14. Еремин Д.И., Кибук Ю.П. Диффреренцированное внесение удобрений как инновационный подход в системе точного земледелия // Вестник КрасГАУ. - 2017. - № 8. C. 17-26.

\section{Literatura}

1. Renev E.P., Eremin D.I., Eremina D.V. Ocenka osnovnyh pokazatelej plodorodija pochv, naibolee prigodnyh dlja rasshirenija pahotnyh ugodij V Tjumenskoj oblasti // Dostizhenie nauki i tehniki APK. - 2017. T. 31. - № 4. - S. 27-31.

2. Fisunov N.V., Fedotkin V.A., Ivanenko A.S. Jeffektivnost' vozdelyvanija jarovoj i ozimoj pshenicy $v$ Tjumenskoj oblasti //Agroprodovol'stvennaja politika Rossii. - 2015. № 10 (46). - S. 38-41.

3. Eremin D.I. Produktivnost' zernovogo $\mathrm{s}$ zanjatym parom sevooborota $\mathrm{v}$ uslovijah Severnogo Zaural'ja: avtoref. dis. ... kand. s.-h. nauk. - Tjumen', 2002. - $18 \mathrm{~s}$.

4. Abramov N.V., Sherstobitov S.V. Differencirovannoe vnesenie udobrenij $s$ ispol'zovaniem sputnikovoj navigacii // Agrohimija. - 2018. - № 9. - S. 40-49. DOI: 10.1134/S000218811809003X.

5. Ljubimova A.V., Eremin D.I. Izuchenie geneticheskogo raznoobrazija sortov ovsa sibirskoj selekcii po avenin-kodirujushhim lokusam // Agroprodovol'stvennaja politika Rossii. - 2017. - № 9 (69). - S. 70-74.

6. Eremin D.I., Gruzdeva N.A., Eremina D.V. Izmenenie gumusovogo sostojanija seryh lesnyh pochv Vostochnoj okrainy Zaural'skogo Plato pod dejstviem dlitel'noj raspashki //Pochvovedenie. - 2018. - № 7. - S. 826835. DOI: 10.1134/S0032180X18070110.

7. Kurachenko N.L. Morfologija strukturnoj organizacii chernozemov i seryh lesnyh pochv Krasnojarskoj lesostepi // Vestnik KrasGAU. 2009. - № 2. - S. 28-33.

8. Kurachenko N.L., Hizhnjak S.V. Prostranstvennoe var'irovanie strukturno-agregatnogo sostava chernozemov i seryh lesnyh pochv Krasnojarskoj lesostepi v predel'no odnorodnyh uslovijah pochvoobrazovanija // Vestnik Altajskogo GAU. - 2010. - № 1 (63). S. 35-40.

9. Eremin D.I., Gruzdeva N.A. Vlijanie antropogennogo faktora na mikroagregatnyj sostav seryh lesnyh pochv // Sibirskij vestnik sel'skohozjajstvennoj nauki. - 2018. - T. 48. № 1. - S. 28-37. DOI: 10.26898/0370-87992018-1-4.

10. Eremin D.I., Gruzdeva N.A. Granulometrija pahotnyh seryh lesnyh pochv Severnogo Zaural'ja // Izvestija Orenburgskogo GAU. 2018. - № 1 (69). - S. 18-22.

11. Eremin D.I., Eremina D.V. (2017). Influence of transport infrastructure on water permeability of soil of Western Siberia. IOP Conference Series: Earth and Environmental Science 90. DOI: org/10.1088/1755-1315/90/1/012111.

12. Rzaeva V.V. Kachestvo osnovnoj obrabotki pochvy $v$ severnoj lesostepi Tjumenskoj oblasti // Vestnik KrasGAU. - 2017. № 12 (135). - S. 29-33.

13. Gruzdeva N.A., Kotchenko S.G., Eremin D.I. Dinamika soderzhanija i zapasov gumusa $v$ agroseryh lesnyh pochvah Severnogo Zaural'ja // Plodorodie. - 2017. - № 3 (96). S. 16-19.

14. Eremin D.I., Kibuk Ju.P. Differencirovannoe vnesenie udobrenij kak innovacionnyj podhod v sisteme tochnogo zemledelija // Vestnik KrasGAU. - 2017. - № 8. - S. 17-26. 